ORIGINAL RESEARCH ARTICLE

\title{
Counter-Clock World: How Planning Backwards Helps in Moving Forward in Collapsing Environments
}

\author{
Christian Stutz, Antti Ainamo, and Juha-Antti Lamberg*十+ \\ 'Jyväskylä School of Business and Economics, University of Jyvaskyla, Jyvaskyla, Finland \\ ${ }^{2}$ School of Business and Governance, Tallinn University of Technology TalTech, Tallinn, Estonia
}

\begin{abstract}
Research on corporate decline and turnarounds as well as the strategic use of history have so far remained two separate research fields. We integrate these two fields with a thought experiment, proposing ways in which strategists can work with, and through time in managing and turning around declines. Our thought experiment involves two very different types of analogies: a textual one from Philip K. Dick's science fiction novels, on the one hand, and a visual one from Einsteinian relativity science, on the other hand. Inspired and informed by these different conceptualizations of the past and time, we develop four forms of backward strategizing to successfully manage a struggling corporation on the brink of environmental collapse. The strategic options, presuming that managers are historically conscious agents embedded in time, direct corporations to go back in history, in actual terms, or in a fictional or mythological one - and thus to initiate a past-related rebirth. By offering a more nuanced and complex understanding of temporality and history, our perspective urges scholars to further unpack historical dimensions in managerial cognition of time.
\end{abstract}

Keywords: Science fiction; Organizational decline and collapse; Strategic renewal and corporate turnaround management; Uses of the past; Analogical reasoning; History; Temporality

Handling Editor:Thomas Roulet; Received: 9 January 20 I8; Accepted: 25 April 2020; Published: 19 March 2021

A $\mathrm{n}$ important topic in strategy is the exploration of how to strategically renew and turn around a corporation that encounters a situation where the economic environment suddenly worsens (Schmitt, Barker, Raisch, \&Whetten, 2016). Under certain environmental conditions, such as at a time of industry decline (Arogyaswamy, Barker, \& YasaiArdekani, 1995) or at a time of technology transition (Knott \& Posen, 2009), a firm is threatened by unpredictable external influences, often at an accelerating rate. These kinds of conditions foster organizational decline, a process in which "a firm's performance or resource base deteriorates over a sustained period of time" (Trahms, Ndofor, \& Sirmon, 2013, p. 1278). Research dealing with this more general topic of organizational decline has long engendered discussions reflecting the concerns and challenges managers face when changes in their environment render the existing firm strategies ineffective (Huff, Huff, \& Thomas, 1992; Ndofor, Vanevenhoven, \& Barker,
2013 ; Pearce \& Robbins, 1993). To align the firm's strategy with such a changing environment, scholars have been apt to prescribe firms a strategic turnaround (Morrow, Sirmon, Hitt, \& Holcomb, 2007; Pandit, 2000; Robbins \& Pearce, 1992; Schmitt \& Raisch, 2013), rejuvenation (Stopford \& Baden-Fuller, 1990), or renewal (Huff et al., 1992; Schmitt et al., 2016) to denote the efforts of managers "that allo[w] organizations to alter their path dependence by transforming their strategic intent and capabilities" (Schmitt, Raisch, \& Volberda, 20। 8, p. 85).

In prescribing turnaround, rejuvenation, and renewal, strategy scholars have also referred to elements of and/or uses of a firm's 'past' and 'history.' For instance, to battle declining performance, scholars have suggested that a firm should attempt to strengthen or shrink back to its "historic resources and capabilities" (Arogyaswamy et al., 1995, p. 509, italics added), use a "scaled-back version of its preexisting strategy" (Robbins \& Pearce, 1992, p. 290, italics added), or radically"depart from

†Authorship in reverse order of seniority, all authors contributed equally.

*Corresponding author: Juha-Antti Lamberg, Email: juha-antti.lamberg@jyu.fi 
past competitive posture" (Pearce \& Robbins, 1993, p. 626, italics added). Scholars have also emphasized temporal characteristics in responding to crises. For instance, Barbero, Martínez and Moreno (2020) show that 'time aggressiveness' - how early and quickly a declining firm implements changes - is positively related to turnaround performance. Schmitt et al. (2016) propose that CEOs must interpret the temporal urgency correctly to enhance the chances of a successful turnaround.

Although this research has advanced our understanding of temporal and historical dimensions of managerial cognition in turnaround situations, there is a scarcity of knowledge in specifying why and how such processes might actually unfold. This kind of oversight is hardly surprising. It is only a recent development that strategy scholars have begun to attend to calls for research to elucidate the role of the past and history in situations of declining environments (Schmitt et al., 2016; Suddaby \& Foster, 2017; Suddaby, Foster, \& Trank Quinn, 2010; Vaara \& Lamberg, 2016; Wadhwani, Kirsch, Welter, Gartner, \& Jones 2020).

Within this context, the purpose of this article is to understand and elucidate the role of history in the management of organizational decline and collapse. Our mission is twofold. We offer both guidance to corporate managers facing conditions of organizational decline by providing a more comprehensive theorization of time and history, and aim to theoretically understand the challenges of such processes. To reach these goals, we deploy a radical thought experiment that involves analogical reasoning at three stages of our argument (cf. Ketokivi, Mantere, \& Cornelissen, 2017). First, we present the 'uses of the past' theory as a new lens - and core analogy - to interpret the behavior of managers facing collapse situations as historically conscious agents embedded in time. Then, we engage with the novels of the science fiction (SF) author Philip K. Dick (1928-1982). This choice builds on a notion that SF can serve as an alternative for empirical data to generate and explore new ideas (see Ketokivi et al., 2017). A central theme in Dick's writings is a "world of pre-established disharmony" (Lem, 1975, p. 59), where the "development of civilization continues but is as it were crushed by itself" (ibid, p. 63). While there is no overall paradigm in Dick's work, its anomalies point to a co-existence of multiple times and parallel worlds, as well as human agency under conditions of almost chaotic environmental decline. Reading a collection of his novels (especially CounterClock World, 1967 '2002'; Ubik, 1969 'I99I', we realized that we can learn a lot if we treat his SF as a source of new ideas to challenge existing research on strategic visioning and choices in declining environments. Therefore, we frame the strategic choices in conditions of environmental decline analogous to the behavior of Dick's stage actors in his worlds of unleashed decay.
To provide credibility to the ideas that we derive from his work, we then ground his imaginative work in general principles of science, which is our third analogical step. In particular, we draw from the work of the German mathematician Hermann Minkowski (2012), whose life and work on the theory of 'spacetime,' complementary to Einstein's (1905) theory of relativity, precede those of Dick. We consider Minkowski's paradigmatic theory about multiple times and spaces to be a model on which Dick might have built his imaginative thinking. Minkowski's theory has the added advantage that it helps to visualize relative motions at different times and how these relate to one another. Many times and spaces are shown by him to co-exist so that experienced reality, in essence, can be said to be timeless (Petkov, 2012; Skow, 2015).

By coupling the scientific paradigm of multiple spacetimes with Dick's writings, we discover and conceptualize what we call 'backward regression towards actual, fictional or mythological past' - a set of past-related turnaround strategies to thwart an organization's decline, avoid collapse, and steer the organization back towards better times. More specifically, we develop four forms of backward strategizing, that is, 'repenting the actual past'; 'restoring an actual past'; 'imagining a fictional past'; and 'inventing a mythological past.' Each describes a historically conscious strategic option, drawing from a core metaphor of Dick's writing, and aligned with a particular set of ontoepistemological assumptions of the Minkowski spacetime. Also, we visualize each strategic option in a process model that explains how backward regression of an organization may actually work and look like.

As our primary contribution, we advance research on turnaround management and strategic renewal in collapsing situations by outlining past-related strategic options. We propose that one logical direction for corporate managers to seek rescue is to look back before the point at which the downturn started - to go back in history, in actual terms, or in a fictional or mythological one - and thus to initiate a past-related rebirth. Additionally, we make a contribution to the 'uses of the past' theory as well as advancing the methodological use of analogies. In the further text, we begin our argument by juxtaposing our approach with the existing literature on strategic renewal in declining environments.

\section{Theoretical grounding}

\section{Strategic renewal in declining environments}

A traditional topic in strategy research has been the examination of organizational decline and turnaround situations where a firm encounters the challenge of a continuous decrease in its performance and/or resource base following periods of prosperity (Arogyaswamy et al., 1995; Huff et al., 1992; Pandit, 2000; Robbins \& Pearce, 1992, 1993; Stopford \& Baden-Fuller, 1990). 
Conventionally, this literature presumes a multi-stage model that describes the response factors influencing managerial decision and cognition, which mediates the cause of the decline, and the strategic actions taken (Trahms et al., 20 I 3). In situations of decline, existing strategies are ineffective (Pearce \& Robbins, 1993; Schmitt et al., 2018; Trahms et al., 2013). As causes, research has explored external changes in the environment (e.g., Arogyaswamy et al., 1995) and internal problems (e.g., McKinley, Latham, \& Braun, 2014).

Recently, Schmitt et al. (2016) offered a new framework that explains the conditions of an environment that may trigger a firm's decline. Building on population ecology (Hannan \& Freeman, 1984), they provide a two-dimensional matrix to show that environmental decline situations differ. They consider the specific resource space for a population of firms (i.e., quantitative size and qualitative shape), and the rate at which the decline occurs (i.e., gradual or sudden) in particular. Whereby their two-dimensional conceptualization assesses any environmental decline situation, we narrow our definition of a declining environment to the most urgent, that is, environmental collapse (viz. sudden decline in shape).

Many scholars have identified appropriate strategic actions that a firm may take to stop its downturn (i.e., the phases of the renewal journey; Morrow et al., 2007; Schmitt et al., 20 I8; Tangpong, Abebe, \& Li, 2015; Trahms et al., 2013). Proposed strategic choices include retrenchment (i.e., a combination of asset reduction and cost-cutting activities) as well as the adoption of incremental or discontinuous renewal or recovery strategies (i.e., a set of strategic reactions designed to turn around decline) (Danneels, 20I I).

Managerial cognition is often suggested as the crucial mediating mechanism in how top management perceives and interprets the downturn and reverse decline (Trahms et al., 2013). Firms with different managerial cognition within the same context choose different strategies (Child, 1997; Schmitt et al., 2016). When a corporate manager recognizes conditions of environmental collapse (i.e., a decline of shape), the focus shifts to recognizing the urgency of the situation. When interpreted 'correctly' (Schmitt et al., 20।6), the manager works to initiate a renewal strategy that breaks with the earlier path (i.e., discontinuous renewal).

While this literature has identified the importance of the temporal dimension in cognitive processes, we contend that this conceptualization is at least one way underdeveloped: it portrays strategizing that would be defined by an external, linear, and evenly measurable manifestation of time. By contrast, recent research on the uses of the past has shifted attention to recognize that actors may have "considerable agency to act upon time" (Wadhwani et al., 2020, p. I4; see Suddaby \& Foster, 2017 ; Vaara \& Lamberg, 2016). Such research seminally points to why and how managers may vary in their awareness of both their agency for managing change in historical time, and constraints imposed by the historical past (Suddaby \& Foster, 2017). In sum, the turnaround literature may have made references to the strategic options that lie in the more distant past (see, e.g., Arogyaswamy et al., 1995, p. 509, Pearce \& Robbins, 1992), and renewal literature has mainly seen history as a problem in terms of inertia and the inability to get rid of obsolete capabilities (e.g., Danneels, 201 I; Kim \& Pennings, 2009). Evidently, bridges between theoretical discussions, and the practical relevance of or the pragmatic use of the past have yet to be built.

\section{A historically conscious perspective of strategic renewal}

Important for our theoretical work, strategy scholars have recently shown a growing interest in incorporating the past, history, and historical embeddedness into their research (Suddaby, 2016; Suddaby \& Foster, 2017; Vaara \& Lamberg, 2016 ; Wadhwani et al., 2020). In these writings, the firm's past is a resource for a corporate manager that can "be shaped and manipulated to motivate, persuade, and frame action both within and outside an organization" with relative malleability (Suddaby et al., 2010, p. 147). Interpretive and social constructionist research streams have shown how the use of history in strategizing can provide a sense of continuity (Brunninge, 2009) or discontinuity (Ybema, 2014) from the past (Foster, Coraiola, Suddaby, Kroezen, \& Chandler, 2017). Another research stream holds a more objectivist stance towards the past, emphasizing the past's influence on the present. This research recognizes the constraining forces of conditions that shape rhetorical history-uses by managers (Cailluet, Gorge, \& Özçağlar-Toulouse, 2018; Sasaki, Kotlar, Ravasi, \& Vaara, 2020; Sinha, Jaskiewicz, Gibb, \& Combs, 2020). A third group of strategy scholars has begun considering the value of (non-symbolic) remnants from the past, such as the reuse of legacy technology (Raffaelli, 2018), its usefulness in innovation (De Massis, Frattini, Kotlar, Messeni Petruzzelli, \& Wright, 20 16; Erdogan, Rondi, \& De Massis, 2019), and even the restoration of past strategic options (Miller, Gomes, \& Lehman, 2019). Suddaby and Foster (2017) argue that managers hold implicit models of history (i.e., different types of historical consciousness) that influence their ability to manage change.

On the one hand, according to Suddaby and Foster (2017), managers can emphasize objective assumptions about history: the past is, in this view, a sedimentary accumulation of events and experiences, forces that limit today's actions. This perspective of the past restricts human agency and makes change extremely difficult. As Suddaby and Foster (2017, p. 20) write "those who see the past as an objective reality might reasonably be expected to also see the future as highly influenced if 
not fatalistically determined by history." Therefore, such a view is more likely to lead to path-dependent actions that may ultimately end in dissolution. On the other hand, managers may believe that the past is a repository of facts that offer skilled rhetoricians a high degree of agency in manipulating the past and present for future interests. For these purposes, managers may consider the strategic value of symbolic and substantive remnants from the past. Therefore, Suddaby and Foster (20 I 7) argue that a stance that views history as more malleable allows for more agentic behavior.

Despite the seminal kinds of advances, the above studies have, as of yet, provided only limited insights into the crucial roles that the past can have in strategic processes and practices in terms of historical thinking in environmental decline situations. To elucidate this phenomenon, as foreshadowed above, we draw on Dick and Minkowski to propose that a historical perspective to strategic renewal in a declining environment potentially leads to novel insights. To move towards that goal, we proceed with our thought experiment by first considering Philip K. Dick's imaginative thinking, and then Herman Minkovski's hard sciences. We start with the former to illuminate the relations between cognition, temporality, and strategic actions in declining environments.

\section{Imagining a counter-clockwise world in decay with ubiquitous potential}

In organizational studies, SF themes have attracted much and growing attention since the turn of the millennium (Aroles, Clegg, \& Granter, 2019; Beyes, Costas, \& Ortmann, 2019; Czarniawska and Gustavsson, 2008; Higgins, Lightfoot, Parker, \& Smith, 2001; Parker, Higgins, Lightfoot, \& Smith, 1999). We leverage this attention by applying an 'analogical reasoning' approach to SF. Following Ketokivi et al. (2017, p. 642)'s understanding of analogical reasoning, we take Philip K. Dick's SF as "grounds of [our] argument," similar to how empirical researchers use empirical data to challenge and complement existing theories. More specifically, we consider Dick's novels as illuminating thought experiments (Cooper, 2005; Mey \& Weber, 2003) for research on strategic renewal in environmental collapse, because, as in many other works in SF, themes of catastrophe and system collapse are omnipresent.

We are especially interested in Dick's treatment of time and agency in near-death catastrophic situations. According to Lem (1975, p. 60), "the theme of catastrophe had been so much worked over in SF that it seemed to be played out until Dick's books became a proof that this had been a matter of frivolous mystification." His particular invention is a world of frenzied physics, "[a] world gone mad, with a spasmodic flow of time and a network of causes and effects which wriggles as if nauseated" (ibid, p. 62). This world suffers from elementally unleashed entropy, that is, the idea that order in nature tends to return to chaos.

Rather than fighting back against entropy, Dick appears more or less to ignore this, both as a phenomenon and as a concept. At least superficially, he sidesteps conventional assumptions associated with entropy, such as that, in entropy, time has a specific direction, and that a system, according to entropy, tends to become more complex over time. No overall paradigm appears to hold, time flows in several directions; things get both simpler and more complex. Most importantly, these paradoxical entropic conditions do not appear deterministic to an individual but, quite the contrary, an individual can initiate interventions to break with path-dependent developments. That is, if she, by birth or rebirth, possesses the required potential or if she employs an apparently 'magical tool.' In the novel called Ubik (Dick, 1969), for instance, the stage actors can employ a 'spray can' that can give the world a counter-clockwise spin (see Table I).

Often, the particular world or worlds, and the participants imagined by Dick in it or them, amount to a complicated web of temporal directions, local collapses, and interventions. This complicated web is then 'bootlegged' by one or more inscrutable factors in the plot (Kerman, 1991). Following Lem (1975, p. 59):

The peculiarities of Dick's worlds arise especially from the fact that
in them it is waking reality which undergoes profound dissociation
and duplication. Sometimes the dissociating agency consists in
chemical substances (of the' hallucinogenic type - thus in Three
Stigmata of Palmer Eldritch); sometimes in "cold-sleep" technique
(as precisely in Ubik); sometimes (as in Now Wait for the Last Year)
in a combination of narcotics and "parallel worlds."'The end-effect
is always the same: distinguishing between waking reality and visions
proves to be impossible.

In what follows, we provide in more detail our reading of the two books we consider to offer imaginaries of particular worth to research into conditions of decline and uses of history for

Table I. Management by Ubik spray

\begin{tabular}{ll}
\hline Description & Representative quotes \\
\hline $\begin{array}{l}\text { Ground } \\
\text { assumption }\end{array}$ & $\begin{array}{l}\text { 'Prior forms ... carry on an invisible, residual life in every } \\
\text { Intervention }\end{array}$ \\
tool & . ' '... spray is ... a counter-clockwise spin ... for a \\
specified time ... greater vitality ... within our \\
environment' \\
• '... uncovers the prior stages inherent in configura- \\
tions of matter.' \\
• '... interfering with the natural process of life and \\
death.'
\end{tabular}

Source: Dick (1969) 
renewal. Ubik (1969 'I99I') has received continuous and favorable attention since it was published. In contrast, Counter-Clock World (1967 '2002') is not among the best of Philip K. Dick's works according to experts in the SF genre. Taken together, we argue that these two books work as a thought experiment in how factual or imaginary 'parallel worlds' can have a catalytic effect to give 'rebirth' to organizations. We start with a reading of Counter-Clock World, sketching out its paradoxical ideas but also envisioning a radical strategy for how to overcome corporate decline. We refine this sketch with a reading of Ubik, before moving on to Minkowki's spacetime theory to unpack Philip K. Dick's and our own imaginaries.

\section{Counter-clock world - parallel worlds, each one deterministic}

The common understanding is that Counter-Clock World is a book inconsistently and badly written, essentially pulp fiction, and enjoyable only by the most serious of SF fans. For strategy scholars, we argue, this book is fantastically insightful. The story goes as follows. For undisclosed reasons but related to 'WW4, Earth has moved into a 'Hobart Phase.'Time goes backwards rather than only forwards. Many entities and functions (but not all) regress. Examples of this include the fact that the central task of libraries is to destroy books when they become new. People who died long ago now come back to life. Cigarettes are no longer smoked; instead, people blow smoke into discarded butts until they grow back into whole new cigarettes.

In this world of the counter-clockwise, two types of people function and inter-breed: together with the conventional 'oldborn' conceived along the age-old methods of Nature, there are also 'new-born' who have been dug out of their graves. The new-borns live their lives in reverse (producing, for example, fresh food for refrigerators) in comparison to the old-born. The job of Police Officer Tinbane, an old-born, includes easing the dead out:

This part of his job he liked least. The cries of the dead; he hated that sound, and he heard them, the cries, so much and so many times. Men and women, mostly old but some not so old, sometimes children. And it always took the digging crew so long to get here ... Distantly, from beneath the ground, the impotent, ancient female voice called,'Please somebody; I want to get out. Can you hear me? I know somebody's up there; I can here you talking ... what year is this?' the elderly voice called back. 'How much time has passed? Is it still 1974? I have to know; please tell me sire.'Tinbane said, 'it's 1998.'

The old-born have not yet experienced a grave, whereas the new-born are veterans. Each new-born, after a commercial auction regarding a suitable 'place location,' finds his or her appropriate place in either the clockwise world or the counter-clockwise one. It is against the law to dig anyone out of their grave before the corpse has been properly new-born under the ground and is hence 'formerly late' in a way that is indisputable. Benefits for the old-born appear in the recombination of their experiences with those of the new-born. Inter-world marriage is one form for such recombination to happen fruitfully. The challenge of such a marriage is that a new-born becomes younger and younger (until the copulation of their parents) when, in natural contrast, a conventional old-born continues to become older until she dies. Old-born Lotta Hermes is married to Sebastian Hermes, a new-born. In her own words: 'I'm married to a man who lay dead down below; once. When I was born, Sebastian was dead, and he remained dead until I was twelve years old.'

In sum, an important idea for researchers into history-based strategizing is that of introducing new assumptions about how people function under conditions of a declining environment. Just as in Dick's worlds, the world can regress to a state in which there are parallel old- and new-born layers of existence, whereas people accept, without urgent activism, the new normal.

\section{Ubik - parallel worlds and human and artificial forms of agency}

Ubik is generally viewed as one of Dick's best books. Like in many of these books, the 'meta-narrative' deals with the parallelism between current and regressing events. The plot is considerably more sophisticated than in Counter-Clock World. The parallelism is manifested as changes in material things and material contexts (but not, in this work, in human physiology). What is 'truth' or 'real' and the nature of imagination unfold in many dramatic developments in the narrative. Even though many citizens dispute the legality of this practice, very-sick people are kept under frozen conditions - as 'half-lives' - and stored in special' moratorium' facilities before they die so that their living relatives can visit them and communicate with them. When someone is hurt in an explosion on the 'Luna' moon, this person is transferred to one of these moratoriums in Switzerland. At the same time, mysteriously, the explosion catalyzes a process through which cigarettes, cream, and coffee that age beyond their maturity date suddenly become spoilt. Coins also encounter 'rapid decay': a form of evolution that results in them exceeding their period of validity within just a few hours. Machines, devices, and the world's entire technological infrastructure all embark on a process of rapid decline and deterioration. People believed to be physically located amid this decaying infrastructure turn out to be 'somewhere else.' Despite this rapid and very complicated process of decline, complete chaos is never the result. Each artifact preserves its core function. Technological artifacts do not disintegrate into their component parts as entropy would suggest; they 'regress' into the past in a predictable manner. That is, things like 
televisions or elevators suddenly roll back a technological generation or two, re-becoming 'traditional' rather than remaining modern.

The rolled-back technology and artifacts (cars, pens, elevators) may look different but continue to function, sometimes in ways that are more user-friendly and make their users feel better. In other worlds, the predictability of 'roll-back' conjures up nostalgia (Dick, 1967, p. 146). This regression in technological solutions and methods of use might be permanent, no one knows (ibid, p. 155; see also p. 147).

Many people inhabiting this frenzy world of Ubik attempt to control the conditions of their existence. Some are more talented at this than are others. A little girl has an uncanny natural ability to manipulate both history and the future, but only when the history that is to be changed is sufficiently recent and she is also in the right mood. Throughout the book, the reader little by little perhaps begins to understand the real essence of 'Ubik'- Ubik is a rare but industrially manufactured and commercially-valuable substance available in spray form. Spraying Ubik on anything that is decaying, on a being half-dead, nearly-dead or completely dead, or all of these, delivers a guaranteed bout of instantaneous - even if temporary - revitalization whenever the substance is administered (Dick, 1967, pp. 212-213):

'What is Ubik?' ... A spray can of Ubik ... is a portable negative ionizer ... The negative ions are given a counter-clockwise spin ... so that they cohere rather than dissipate ... for a specific time, anyhow - an increment in the net put-forth field ... which the affected half-lifer experiences as greater vitality.

The important idea that Ubik offers researchers of strategizing is that the process of decay regression offers countless agentic possibilities: for influencing how things eventually unfold over time and in what direction. Such intervention can utilize any form of technology that has ever worked in the past, however distant in time, while also believing in strange revitalization events. In sum, Counter-Clock World can be regarded as a thought experiment in the complicated and dynamic interlacing of several evolutionary strands, while Ubik is a thought experiment in human agency and its limits, and the randomness that results from exceeding such limits. Given this, cognition and beliefs about the past-present-future relationship in multiple worlds enters center stage to steering into a future that is better than the present.

\section{Grounding counter-clock world and Ubik in physics and physical reality}

Even though Dick's visions have long been considered just strange at the point in time when he wrote his books, his imaginative writing has since been found to correspond with many basic tenets of modern physics, for example. Methodologically, we draw from Ketokivi et al.'s (2017, p. 644; italics in original) insight that we can justify a new analogy by showing its alignment with a 'more foundational paradig $[\mathrm{m}]$ that host [s] the individual analogies.'Therefore, we present Einstein's theory of special relativity - and Minkowski's implication thereof - as our foundational paradigm. By evaluating the fit with Dick's musing about determinism and agency, we then use the visual representation of the Minkowski spacetime to ground Dick's SF in physical reality.

\section{Einstein's theory of special relativity and the Minkowski spacetime}

Einstein's (1905) theory of special relativity has successfully challenged conventional conceptions by which the passage of time is thought as given to us (Skow, 2015). His theory, which precedes his general theory of relativity published in 1913, postulates that inertial observers in relative motion have different times. He reached the conclusion through a thought experiment à la Galileo. A variant of the thought experiment is known as the 'twin paradox.'That is, twins who depart from the same location, but with one traveling back and forth to outer space at light speed, may have aged by different amounts when they meet up again (Skow, 2015). Thus, Einstein established the relativity principle (that is, that many times and spaces exist).

The mathematician Hermann Minkowski (2012) was the first to successfully decode the implications of the relativity principle. According to Minkowski, the Universe is a four-dimensional world with time as the fourth dimension, since then known as the Minkowski spacetime. His mathematics represents space and time analogous to ordinary Euclidean geometry. This means that it deals with 'metrical' distances. The geometrical structure of the Minkowski spacetime has since become an integral part of more recent theories of time, such as the block universe theory of time and the moving spotlight theory (Skow, 2015). Minkowski's basic theory has the added advantage of visual power (see Figure I), which is appropriate to ground Dick's imaginative thinking in parallel worlds.

\section{The visual representation of spacetime}

In Minkowski world of spacetime, time $t$ is treated differently than, but in interconnection with, space and its dimensions of length $x$, height $y$, and depth $z$. Often, as in Figure I, the Minkowski spacetime is conventionally depicted as two-dimensional, comprising only the $x$-axis of space and time $t$ as the second axis.

The key to understanding Minkowski spacetime is to understand his key premise or assumption that each of the infinitely possible spaces $x$ exist for just one very brief 


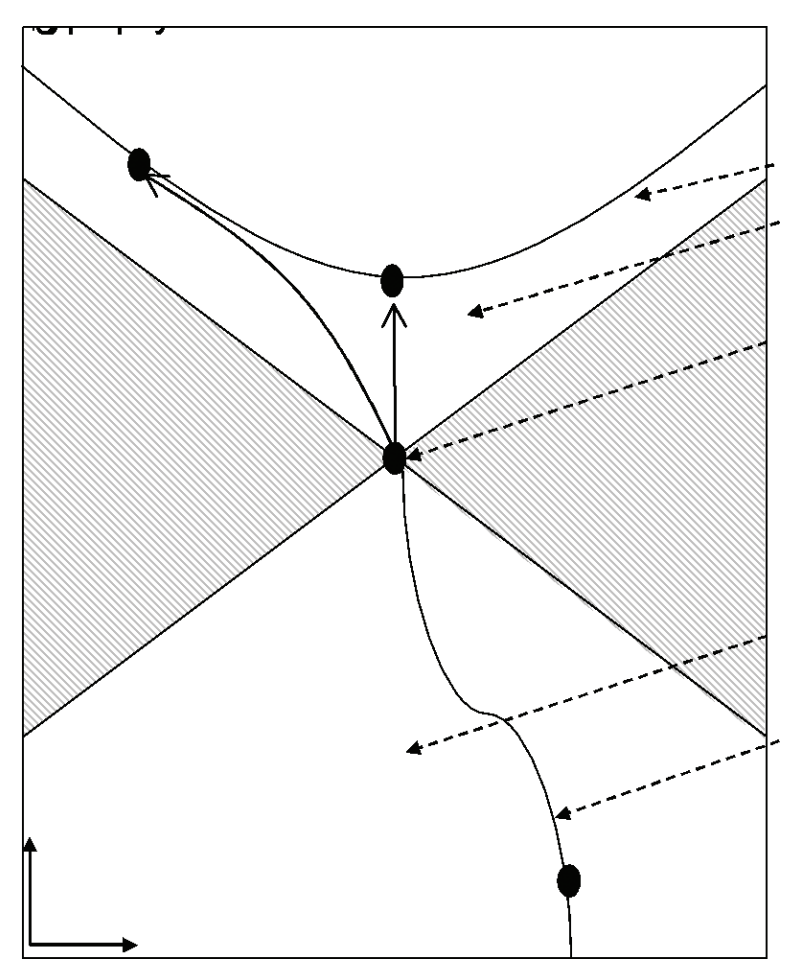

Figure I. The Minkowski spacetime

instance, the dimension that makes up time $t$. In this 4D-view of space and time (or 2D-view, as in Figure I), one can imagine the instantaneous existence of a substantial thing or artifact (such as a television or a corporation) as a four-dimensional point of spacetime (i.e., a 'worldpoint'), represented by the point of space $x, y, z$ at a particular time $t$ (Minkowski, 2012).

By imagining the course of life of any substantial thing or artifact, one can then think of how the time difference $d t$ corresponds with changes in the $x, y, z$ of its spatial coordinates. To describe the motion of the substantial thing or artifact from $P$ to the new worldpoint $P^{\prime}$, we just need to indicate where it is in each spacetime and draw the curve, that is, a 'worldline' (e.g., the curve from P to P' in the figure). For Minkowski (20I2, p. 40), "the whole world presents itself as resolved into such worldlines, and I want to say in advance, that in my understanding the laws of physics can find their most complete expression as interrelations between these worldliness" allowing us to interpret Dick's writings about the existence of different times and parallel worlds.

Equipped with the Minkoski spacetime, an arbitrary worldpoint $P$ can be taken as the origin of our thought experiment. To map out all possible trajectories of P (not only the physical or actual trajectory), Minkowski introduces the idea of 'lightcone.' Owing to complicated mathematics related to the speed of light, this notion comprises all events that come logically before or after $\mathrm{P}$, connected by a timelike vector ('motion'). The future lightcone ('Nachkegel') comprises all events that one can causally derive from P. In turn, a past lightcone ('Vorkegel') contains all the events in spacetime from which P is causally affected ('send light to P'). The spacetimes outside the two light cones are 'elsewhere regions.' That is, these worldpoints are causally disconnected from $P$ (because, building on the idea of speed of light, worldpoints in this area would have propagated more quickly than light, which is impossible). For Minkowski, any worldpoint within the elsewhere region "can be regarded, by a choice of the reference system, as simultaneous with $[\mathrm{P}]$ as well as earlier than [P] or later than [P]" (Minkowski, 20I2, p. 47, italics in original).

An idea analogous to circles with center $P$ in Euclidean geometry is the idea of 'hyperbolas.' By this, Minkowski means that there are always two different types of times in the same reference frame. On one hand, coordinated time $t$ represents the moving clock (as in a calendar). On the other hand, proper time is measured by length $t^{\prime}$ along a timelike worldline. The proper time (i.e., the measured distance of the timelike worldline) relates to Einstein's twin paradox in that proper time depends on the relative motion of the substantial thing. In Figure I, the hyperbola of the future lightcone can be thought of as the "worldline of a substantive point, which represents its motion that increases asymptotically to the velocity of light" (Minkowski, 2012, p. 47).

Minkowski differentiates between inertial and accelerated motion. Derived from experimental physics, Minkowski considers that a substantial thing moving by inertia offers no resistance to its uniform motion, whereas an accelerating substantial thing resists its acceleration. In spacetime, these criteria are represented by the straightness of the worldline (inertial motion) and the curvature or deformation of the worldline (accelerated motion). As a result, consider that the distances of the worldlines of a substantial thing in motion differ according to its velocity (inertial or accelerated motion). In other words, to reach a comparable physical state (non-P on the hyperbola), the accelerated substantial thing should use two times in her reference frame, proper time $t^{\prime}$ and the coordinated time $t$ (as in inertial motion).

In sum, by delving into modern physics, we understand that the frenzied physics in Counter-Clock World and Ubik are elements that promise to be both an adequate and fruitful framework for a deeper understanding of strategizing in organizational decline. The idea of inertial motion corresponds to path dependence of organization, which results in organizational death after time $d t\left(P^{\prime}\right)$. In turn, the stage actors in Dick's novels demonstrate different strategic options (in parallel worlds, back and forth in time) suitable to extend organizational survival for a relative time $t$ ' (i.e., acceleration of the motion). 


\section{Backward strategizing in collapsing conditions}

In what follows, we derive strategic options from Dick's imaginative thinking and ground the strategic options in a visual understanding of the Minkowski spacetime. To integrate these analogical components with the strategic management of modern corporations, we draw from Suddaby and Foster's (2017) insight that a manager's implicit model of history (or by extension: spacetime awareness) influences his or her strategic decision making. To this end, we clarify the ontological and epistemological assumptions behind a strategic decision. Finally, we discuss empirical examples of what we perceive as previous executions of the alternative renewal strategies that we inferred from our analogical reasoning (Table 2).

\section{Repenting the actual past}

The first view of strategic renewal in environmental collapse emerges from Dick's metaphor of 'moratorium facilities storing half-lives,' which refers to the idea of considering the objective past as a mirror that may engender contemplation. The strategic focus derived from this metaphor emphasizes that a firm might repent of and learn from past mistakes. By understanding the provenance of the present situation - viz., largely a series of coincidences - historical contemplation might serve corporations by "opening up possibility for things being otherwise" (Zundel, Holt, \& Popp, 20 I 6, p. 229). This renewal strategy implies transforming a firm's current activity domain by taking recourse to ideas and mistakes from the past.

Two assumptions, in terms of ontology and epistemology, define this renewal strategy (Suddaby \& Foster, 2017). First, the top management of a firm with declining performance must hold an objective assumption of spacetime. That is, the ontology of the firm's trajectory from the past to the present is seen as 'brute facts' that led to the current situation of decline. In turn, despite the constraining forces of history, this renewal strategy implies that top management can interpret the path

Table 2. Overview of backward strategizing in environmental collapse

\begin{tabular}{lllll}
\hline & Repenting the actual past & Restoring an actual past & Imagining a fictional past \\
\hline Dick's metaphor & $\begin{array}{l}\text { The 'moratorium' } \\
\text { intervention to visit and } \\
\text { communicate with the dead }\end{array}$ & $\begin{array}{l}\text { The 'rapid decay' intervention to } \\
\text { preserve the core function of }\end{array}$ & $\begin{array}{l}\text { 'Bootlegging' intervention to } \\
\text { create a parallel world }\end{array}$ & $\begin{array}{l}\text { The 'talented girl' / 'Ubik spray' } \\
\text { intervention to change history }\end{array}$
\end{tabular}

Implication 'half-life' in the moratorium

The past is a mirror provoking contemplation.

The past is a successful blueprint to be imitated

Focus of strategic Transform the current discontinuous activity domain by learning renewal from past mistakes and rescue some ideas from the past

Assumptions of The ontology of spacetime spacetime

Grounding in

Minkowski spacetime

Empirical example

\section{is objective, the epistemol-} ogy is interpretive (reflexive)

Examining the actual worldline to accelerate motion to Non-P'

Katakura Industries' recovery of an actual

Resetting a firm's past activity domain by restoring and exploiting historic core capabilities and/or strategic intents

The ontology of spacetime is objective, the epistemology is positivist (empiricist) to accelerate motion to AP'

Business exits of mobile phone companies between 1995 and
Relation to known concepts and applications in the uses-of-thepast literature strategy statement to legitimize diversification (Sasaki et al., 2020)

Restoring the actual worldpoint $\mathrm{P}$ 2013 in which many companies, such as Motorola and Nokia, restored a past activity domain (Giachetti \& Marchi, 20 I0; Lamberg, Lubinaitè, Ojala, \& Tikkanen, 2020)

Zundel et al.'s (2016) 'being Miller et al.'s (2018) 'strategy restoration'

Raffaelli's (2018) reuse of legacy technology
The past is seen to be a highly malleable resource to be shaped for future interests of 'what should become'

Approaching a past-related but distinctly new activity domain by imagining what could have been 'possible' in the past (seen from actual present) to trigger a brighter future

The ontology of spacetime is subjective, the epistemology is interpretive (consensus)

$P^{\prime}$ Imagining the non-actual but possible worldpoint FP to accelerate motion to FP

Cadbury's construction of its fictitious corporate history in 1931 that emphasizes the firm's origin in Quaker beliefs about caring for employees (Rowlinson \& Hassard, 1993)

White's (2005) 'fictional history'

Suddaby and Foster's (2017) history-as-sensemaking and rhetorical history
The past is an entirely symbolic space for myth-making to serve future interests of 'what should become'

Approaching an unrelated new activity domain by inventing what should have been the past (seen from an imagined bright future) to trigger its emergence

The ontology of spacetime is subjective, the epistemology is constructivist (relativistic) Inventing the non-actual and impossible worldpoint MP to accelerate motion to MP'

Hendrick's mythological invention of a new brand's past (The Economist, 2019)

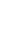


differently (the epistemology). For instance, the management team can critically examine crucial turning points that led to the current situation. In the terminology of Minkowski spacetime, a firm might reconsider the trajectory from P' to P. By collectively reflecting about the past, a firm might find a consensus of what should be done differently in the future. This kind of thinking helps a firm to break from path dependence, since it might accelerate motion to a worldpoint non-P', distinct from inertial organizational death at worldpoint $P^{\prime}$ (Figure 2).

Schmitt et al.'s (2016) framework suggests that the strategy based on repentance might be appropriate in situations of the collapsing environment, which requires a discontinuous renewal. An empirical example is provided by Sasaki et al. (2020): Katakura Industries, originally a Japanese silk producer, had to respond to rising pressures when the firm suffered a setback due to the invention of nylon in the 1940s. To depart from the silk industry and diversify into fiber products and real-estate development, managers affirmed the 'entrepreneurial spirit' needed to legitimize the discontinuous renewal strategy by recovering a segment of a historical strategy statement (i.e., "Family shall be frugal, and business shall be enterprising," see Sasaki et al., 2020, p. 48). Another example concerns organizational wrongdoing in the past (e.g., Janssen, 2013), and how a firm's strategy may be based on shame and sorrow from mistakes made in

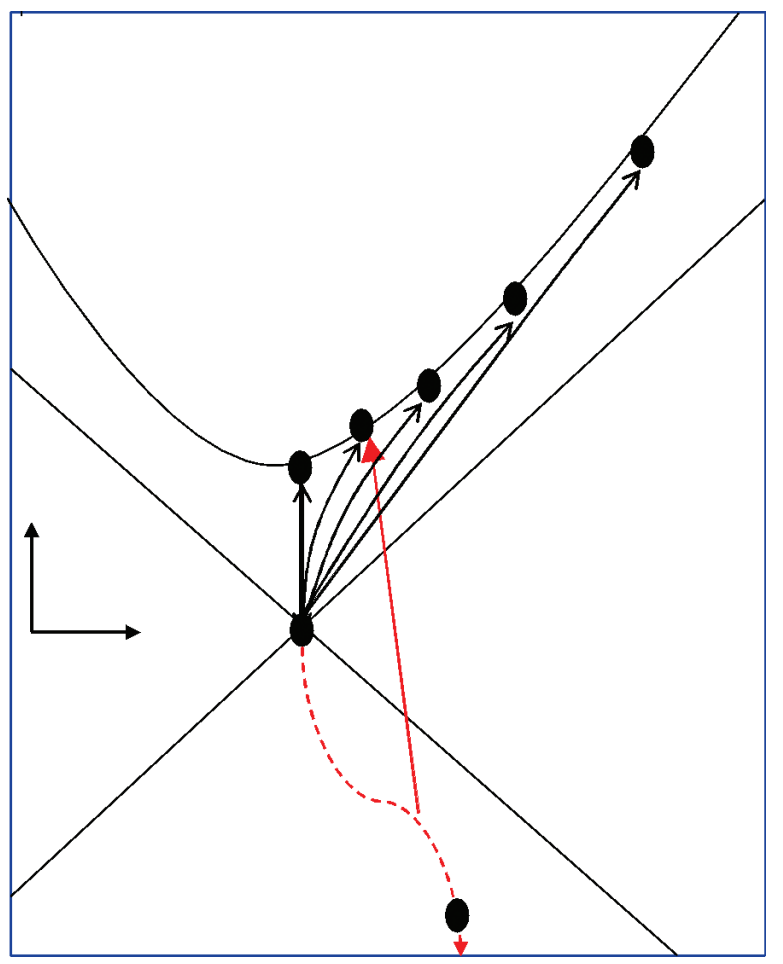

Figure 2. Repenting 'the' actual past the past (e.g., Wiesen, 2003). Overall, repentance is potentially a forceful psychological motivation for a firm's top management to turn around, and look for an entirely different direction and purpose of action.

\section{Restoring an actual past}

The 'restoring an actual past' strategy is the direct application of the 'Counter-Clock World logic,' as suggested by Dick's work. While the 'repenting the actual past' option motivates strategists and managers to project a company's desired direction into the future by reference to the past, the CounterClock World logic translates strategic renewal to a backward projection. The strategist or manager responsible for achieving strategic change chooses a target from the organization's past - a blueprint to be imitated for surviving the collapsing environment. Building on the idea of absorbing slack resources, a company can incrementally release its resources until the organization realizes its imprinted destiny through a set of events similar to those that have been experienced at an earlier point in time. From a conceptual viewpoint, the target is thus a known entity, which offers a powerful message to all stakeholders that hold specific expectations regarding what the organization is and what it should be. This option also enables the discovery of resources forgotten during earlier phases of the organization's development (Figure 3).

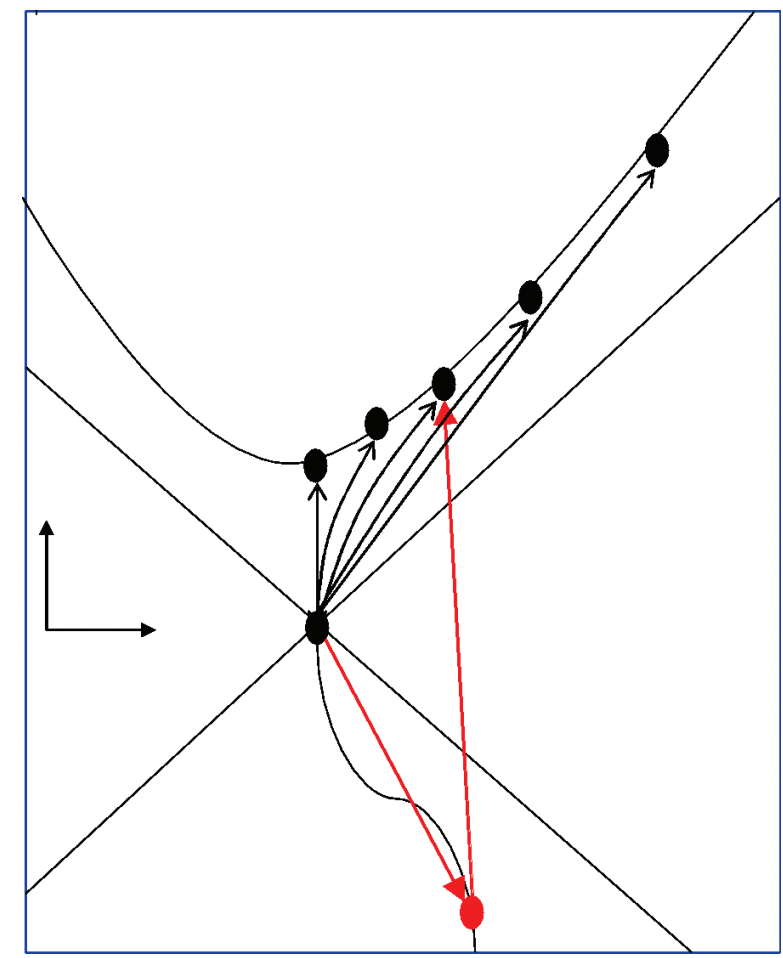

Figure 3. Restoring an actual past 
In alignment with the previous strategic renewal perspective, 'restoring an actual past' requires objective spacetime assumptions but departs in terms of epistemology. While 'repenting the actual past' invites the strategist to be reflexive, this renewal strategy is empiricist in nature. Although this epistemological view is relatively oppressive to change (as history is seen to constrain human agency), exogenous shocks - as in environmental collapse situations - can facilitate change, as they sharpen an understanding of the need for "material change in states of being" (Suddaby \& Foster, 2017, p. 23). In Minkowski's spacetime, this means dislodging the path dependence by going back to an actual - empirically factual - worldpoint P', which might extend survival to worldpoint AP'.

'Restoring an actual past' is identifiable both from existing research literature and known turnaround cases in which firms have unpeeled layers of diversified business activities before returning to their core business. Miller, Gomes, and Lehman (2019, p. 12) deal directly with restoration as a renewal strategy referring to it as "[...] an organization's intentional reinterpretation and reenactment of discontinued aspects of its historical strategy for present use and for the sake of enhancing future performance." Accordingly, the case is not only to use history as a narrative resource or a source of some potential ideas but as a basis for strategic vision. Miller et al's (2019) conceptual ideas resemble older strategy theorizing on core competencies (Barney, 1991) in which each organization was seen to obtain few core competencies suitable for achieving a sustainable competitive advantage. Identification of core competencies should result in vertical disintegration (Jacobides, 2005) so that a new future could be built on a solid set of resources and capabilities. These kinds of choices also potentially lead to strengthening the internal cohesion of a company that may lead to more effective processes, as members of an organization recognize historical layers of an organization that foster nostalgia (Gabriel, 1993) and legitimacy (Suddaby, Bitektine, \& Haack, 2017) of actions.

The recent change in the global mobile phone industry exemplifies the 'restoring an actual past' strategy. The history of the mobile phone industry goes back to the 1980s when pioneers such as Technophone, Mobira, and Motorola launched the first analog mobile phones. These early phones - the first commercial mobile phone was the Motorola DynaTAC 8000X introduced in 1983 - were large, expensive, difficult to use, and technologically close to radiophones (historical overview in Agar, 2013 ). With the arrival of Apple's and Samsung's dominant era (from 2010 onwards), the interesting issue that that practically all firms that once had considerable market shares in the industry divested their formerly profitable businesses and tried to 'restore' another layer of their actual yet fizzled past. When Motorola owners divested their mobile phone business in 2009, their new strategy focused on radio phones suitable for professional use in police forces, firefighting, armies, and traffic control
- essentially the core strategy of Motorola in the 1970s. Nokia, as another example, sold its mobile phone division to Microsoft in 2013 and subsequently concentrated solely on telecommunication networks - a core business of Kaapelitehdas (Cable Factory), a predecessor firm of Nokia Corporations. Accordingly, seeking a nodal point from the past - for example, from an era before intensive diversification - is potentially common while the outcomes demonstrate the non-deterministic nature of such processes.

\section{Imagining a fictional past}

While both preceding strategic perspectives are related to an 'actual' past of a company, the 'imagining a fictional past' strategy takes Dick's thinking in parallel worlds seriously. As Dick's stage actors in his world of elementary unleashed decay, strategists and managers may turn around the fate of their companies by - what Dick would call - 'bootlegging' interventions. This perspective allows strategists and managers to view the past as a highly malleable resource offering ample opportunity to create a new shared sense of 'what has been' and 'what should become.' By imagining a 'parallel world' history grounded in a possible past, this strategy has the potential to provide new strategic guidance, relevant to the environmental context in collapse (Figure 4).

From an onto-epistemological perspective, this renewal strategy departs from an understanding of history as a true

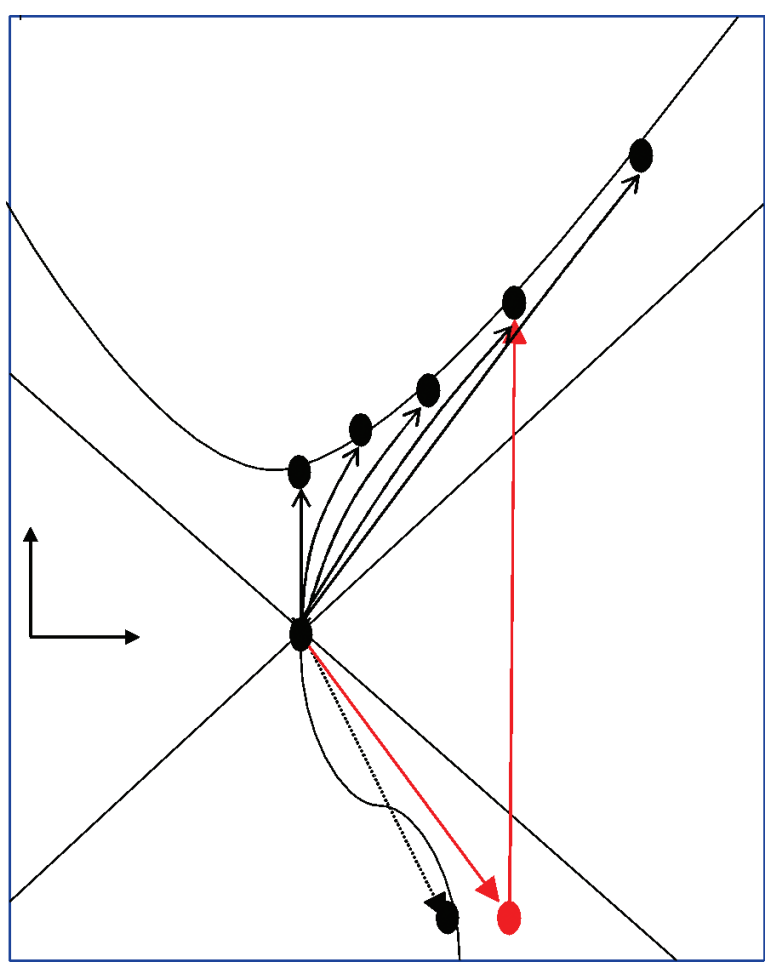

Figure 4. Imagining a fictional past 
account of a firm's trajectory. Instead, it enables managers to mobilize what Hayden White calls a 'fictional discourse' interested in the domain of the real, that is, "what can truthfully [be] said about what it [i.e., the past] could possibly be" (White, 2005, p. 147, italics in original). The conjuring up of a fictional, yet possible past involves artistic treatment of the past. To be effective, a relevant audience must fully recognize this new, if not entirely truthful, image of the organization's past (i.e., interpretive yet consensus-seeking epistemology). After all, this strategy is grounded in the rhetorical tradition of thinking about the past (Suddaby et al., 20 I0), which foregrounds that historiography represents an ongoing attempt to revise previous historical narratives of the past (Lubinski, $2018)$. Aware of the contest of historical narratives, this perspective motivates strategists and managers to imagine -in Minkowski's terminology - a new worldpoint FP. This worldpoint, however, remains in the past lightcone that contains all events in spacetime that could have possibly affected the present worldpoint F. When strategists and managers revise the previous history involving worldpoint $\mathrm{P}$ and this new history proves effective, the survival of the firm is likely to be extended to worldpoint FP'.

There are ample examples in the 'uses of past' literature (Wadhwani, Suddaby, Mordhorst, \& Popp, 2018) that demonstrate the effectiveness of this renewal strategy. Consider, for instance, Rowlinson and Hassard's (1993) analysis of the construction of 'founder' histories of the British confectionery company Cadbury. The 'official' corporate history, as clearly expressed in two publications that marked the centenary celebrations in 1931, emphasizes its origin in Quaker beliefs of the Cadbury family about caring for employees. Rowlinson and Hassard's (1993) contextual analysis reveals that Cadbury decided to draw on history during a very difficult period for the firm. As cited in Rowlinson and Hassard (1993, p. 320), the firm summarized the period as "the first comparatively long period in the history of the firm during which we have failed to go forward ... it is unfortunate that a failure to increase our sales has coincided with a period when other factors have been working against the fullest employment of personnel." In this harsh environment, the firm decided to "draw on appropriate and uncontested events in its past to differentiate itself from other companies" (ibid, p. 322). While Rowlinson and Hassard's (1993) epistemological commitments forbade them from refuting the corporate histories based on their evidently "superior objective[e]" knowledge (ibid, p. 307), it is very clear from their writing that the company imagined a fictional yet possible past - a pseudohistory of its own past.

\section{Inventing a mythological past}

While 'imagining a fictional past' considers the actual past of an organization to a certain extent (i.e., what could have possibly been), 'inventing a mythological past' deals not with the past as such, but with myth-making. That is, the creation of 'ostensibly historical events [...] serves to unfold part of the world view of a people or explain a practice, belief, or natural phenomenon' (Merriam-Webster dictionary). This renewal strategy closely resembles Dick's 'talented girl' / 'Ubik spray' intervention that seeks to change the course of history - starting within the symbolic realm. In the absence of an actual or possible glorious organizational past, Hobsbawm (1983) shows, with a critical mind, that many communities, typically nation-states, purposely invent certain traditions, rituals, and practices to appear grounded in the past, which fabricates a straight line from the past to the present in a teleological sense. For companies, 'inventing a mythological past' is a renewal strategy through which an organization's history is redesigned and presented as a glorious episode, one to be proud of - which evokes new meanings to which stakeholders can commit.

Strategists and managers involved in myth-making of this kind engage themselves in a constructionist-relativistic epistemology, whereby only a very thin line may separate playful inventions of history with a twinkle in one's eye from morally wrongful abuses of history (De Baets, 2009). Beyond this moral question, back to Minkowski, 'imagining a fictional past' refers to the past lightcone, whereas 'inventing a mythological past' transcends its boundaries. In Figure 5, the invented worldpoint MP lies within the 'elsewhere region' outside both past and future lightcones. Inventing a mythological past has little relation to

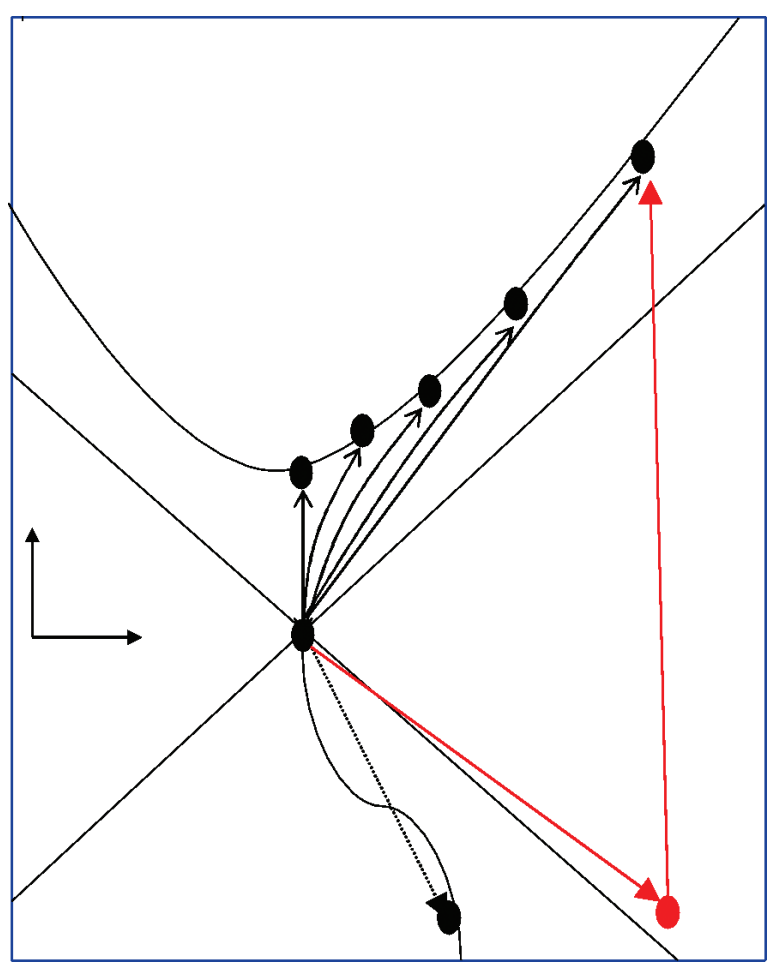

Figure 5. Inventing a mythological past 
the actual passage of time, as it might happen simultaneously, earlier, or later than the present.

A striking example of 'inventing a mythological past' is the gin brand Hendrick's (Vanderbilt, 2019). The Scottish whiskey producer William Grant \& Sons launched it in 1999, without any prior presence in the gin market. Industry experts ascribe the fulminant success of the premium-priced gin to its branding, which uses 'fragments of historical flotsam to spark warm feelings for a novel product.' The packaging is based on an old Victorian apothecary's bottle. The printing of 'Est. I 886' on every bottle simulates its relation to Scottish heritage. The brand's advertising knits this myth to the absurd: In addition to the Scottish heritage, the advertisement creates a parallel world where an incarnation of Alexander von Humboldt in an unspecified time explores the jungle to hunt for new botanicals (as ingredients for a new type of gin). Accordingly, strategists facing a collapsing environment may create just enough (un)believable reality, myths, and legends that customers buy into the products of a new activity domain the firm wishes to pursue.

\section{Discussion and conclusion}

The focus in this article is on understanding the role of temporality and history - whether 'real', invented, or modified - in the management of organizational collapse. We have done so by drawing on a thought experiment and by connecting the so-far separated fields of corporate turnaround and strategic uses of the past. By building on imaginative scenarios presented in Philip K. Dick's SF and Einsteinian relativity science, we propose four alternative past-related strategies for organizations seeking turnaround, and illustrate how the options frame interpretations of managers who find themselves in collapsing environments. Our results contribute in three different directions: research on strategic renewal, analogical thinking, and use of history perspective on organizations.

First, we advance the literature on strategic renewal by elucidating a more nuanced and complex perspective on temporality and history. Prior research has primarily viewed time as an external, objectively and linearly evolving thing (e.g., Barbero et al., 2020), and thereby overlooked the agentic possibilities of working with and through time. As a contrast, inspired by Dick's writing, we clarified the different implicit models of time and history which managers may hold that offer new strategic options in collapse situations. Hence, our perspective on strategic renewal urges scholars to unpack temporal and historical dimensions in managerial cognition further. In addition, our results extend the pool of narrative resources managers may use in the moment of organizational collapse. Instead of merely repeating Kotter's (1995/20 I2) 'burning platform' metaphor to motivate a swift turnaround, managers have a host of alternatives in the different histories of their own company. We also emphasize the role of temporal imagination and creativity in strategic renewal processes, which - we argue - has largely been a burden under the downshifting and other functional means of change policies (cf. Schmitt et al., 2018).

Second, we contribute to the 'uses of the past' theory by exploring and expanding its scope to the strategic renewal literature. This perspective has recently gathered much interest and is arguably emerging as its own field of knowledge in organization studies (see, especially, Wadhwani et al., 2018). By drawing on this perspective, we have shown that this theory has matured sufficiently, so that it can be applied to other knowledge domains, such as the strategic renewal literature. Therefore, our article is an invitation for 'uses of the past' scholars to explore the theory's explanatory potential in other streams of research. Also, our typology adds more nuances to how 'uses of the past' scholars categorize different treatments of the past. For example, repentance and imagining a mythological past is known from the earlier literature as anecdotes yet not as a potential core of a renewal strategy.

Third, we make a methodological contribution to research on analogical reasoning (e.g., Ketokivi et al., 2017) by demonstrating the value of combining different aspects of reasoning by analogy. Especially, we extended the use of analogies to support thought experimentation. Instead of just starting from an analogy, we thought through the hypothetical consequences of the original 'what if' idea to interpret turnaround management as SF. At a more general level, it appears that analogical reasoning combined with large-scale thought experiments has a great potential in strategy theorizing, and opens entirely new avenues to use the wide variety of thought experiment methods as categorized especially in philosophy (Cooper, 2005). For example, our approach resembles 'backcasting' (Dreborg, 1996) in focusing on a potential future which requires a very detailed path built on history (real or imagined as we argue); this example being only one specific mode of the available thought experiments.

Finally, this article delivers a key message to manager practitioners. We have argued that a corporate manager can use her corporation's real, imaginary, or mythological history as both a vision of something better and an operational plan. In this way, the corporate manager can exploit the strong legitimizing effect of nostalgia and authenticity when communicating her strategy for renewal. At the same time, planning also helps to revitalize resources and capabilities that the organization already possesses. Planning backwards primarily consists of creating new conditions, a context for former, presently existing, or future activities. This is because the complexity of intra-organizational and exogenous environmental dynamics means that backwards trajectories never reproduce the past exactly as it once was. Rather, backwards planning acts as a catalyst for new connections and forms of interpretation, working in stark contrast to a conventional view. 
With hindsight, history is not to be judged as a series of errors but rather a cluster of missed opportunities and unimplemented decisions, maybe the reason why and how a struggling organization has ended in a situation where its environment is collapsing. We propose that planning backwards helps managers to identify and understand critical junctures in the past, revisiting or reimagining which ought to be an essential part of renewing strategic thinking in the present. Should the organization lack appropriate history, or if the history it does have is 'useless,' realizing the organization's full potential in different contexts may make it necessary to invent and enact alternative histories.

\section{Acknowledgements}

The authors thank M@n@gement EditorThomas Roulet, Kalle Pajunen, Mirva Peltoniemi, Henrikki Tikkanen, and the three anonymous reviewers for their constructive comments. The paper also benefited from presentations at SMS 2010 Finland Special Conference, and workshops at Universities of Jyväskylä and Aalto. The first and third author received funding from the Academy of Finland for this project, and the second author from Kaute Foundation, Wihuri Foundation, and LSR Foundation for Economic Foundation.

\section{References}

Agar, J. (2013). Constant touch: A global history of the mobile phone. Icon Books.

Arogyaswamy, K., Barker,V. L. \& Yasai-Ardekani, M. (1995). Firm turnarounds: An integrative two-stage model. Journal of Management Studies, 32(4), 493-525. doi: | 0.1 | | |/j. I467-6486. 1995.tb00786.x

Aroles, J., Clegg, S. \& Granter, E. (2019). Death and the Penguin: Modularity, alienation and organising. Culture and Organization, 25(2), 104-1 17. doi: | 0.1080/ | 475955 I.2018.150986 |

Barbero, J. L., Martínez, J. A. \& Moreno, A. M. (2020). Should declining firms be aggressive during the retrenchment process? Journal of Management, 46(5), 694-725. doi: | 0.1 177/101492063188|1563

Barney, J. (199I). Firm resources and sustained competitive advantage. Journal of Management, I7(I), 99-120. doi: 10.1 177/0I492063910 I 700108

Beyes, T., Costas, J. \& Ortmann, G. (20 I9). Novel thought:Towards a literary study of organization. Organization Studies, 40, I- 17. doi: 10.1 177/0 I70 840619874458

Brunninge, O. (2009). Using history in organizations: How managers make purposeful reference to history in strategy processes. Journal of Organizational Change Management, 22(1), 8-26. doi: 10.1 | 08/09534810910933889

Cailluet, L., Gorge, H. \& Özçağlar-Toulouse, N. (20।8). “Do not expect me to stay quiet": Challenges in managing a historical strategic resource. Organization Studies, 39(|2), |8|1-|835. doi: 10.1177/0|708406 |8800। II

Child, J. (1997). Strategic analysis of action, structure, organizations and environment: Retrospect and prospect. Organisation Studies, 18(I), 43-76. doi: I0. I | 77//0 I708406970 I 800 I04
Cohen, P.A. (1997). History in three keys: The boxers as event, experience, and myth. Columbia University Press.

Cooper, R. (2005). Thought experiments. Metaphilosophy, 36(3), 328-347. doi: | 0. I | | |/j. | 467-9973.2005.00372.x

Czarniawska, B. \& Gustavsson, E. (2008). The (D) evolution of the cyberwoman? Organization, I 5(5), 665-683. doi: I 0. I 177/| 350508408093647

Danneels, E. (20II). Trying to become a different type of company: Dynamic capability at Smith Corona. Strategic Management Journal, 32(I), I-3 I. doi: I 0. I002/smj.863

De Baets, A. (2009). Responsible history. Berghahn Books.

De Massis, A., Frattini, F., Kotlar,.., Messeni Petruzzelli,A. \& Wright, M. (20I6). Innovation through tradition. Academy of Management Perspectives, 30( I), 93-| | 6. doi: I0.5465/amp.2015.0017

Dick, P. K. (1967). Counter-clock world. Berkley Paperback.

Dick, P. K. (1969). UBIK.Vintage.

Dreborg, K. H. (1996). Essence of backcasting. Futures, 28(9), 81 3-828. doi: 10.1016/50016-3287(96)00044-4

Einstein, A. (1905). Zur Elektrodynamik bewegter Körper. Annalen Der Physik, 17, 89|-921. doi: | 0. I002/andp. 19053221004

Erdogan, I., Rondi, E. \& De Massis, A. (2019). Managing the tradition and innovation paradox in family firms: A family imprinting perspective. Entrepreneurship Theory and Practice, 44, I-35. doi: | 0.1 | 777/ | 0422587 | 9839712

Foster,W. M., Coraiola, D. M., Suddaby, R., Kroezen, J. \& Chandler, D. (2017). The strategic use of historical narratives: $A$ theoretical framework. BusinessHistory,59(8), I I 76-| 200.doi: I 0. I 080/0007679 I.20 I 6. I 224234

Gabriel,Y. (1993). Organizational nostalgia: Reflections on "the golden age." In S. Fineman (Ed.), Emotions in organizations (pp. I| 8-|4|). Sage.

Giachetti, C. \& Marchi, G. (20 I0). Evolution of firms' product strategy over the life cycle of technology-based industries: A case study of the global mobile phone industry, 1980-2009. Business History, 52(7), I I 23-I I 50. doi: | $0.1080 / 0007679 \mid .2010 .523464$

Hannan, M. T. \& Freeman, J. (1984). Structural inertia and organizational change. American Sociological Review, 49(2), |49-164. doi: 10.2307| 2095567

Higgins, M., Lightfoot, G., Parker, M. \& Smith, W. (200I). Science fiction and organization. Routledge.

Hobsbawm, E. (1983). Introduction: Inventing traditions? In E. Hobsbawm \& T. Ranger (Eds.), The invention of tradition (pp. I-|4). Cambridge University Press.

Huff, J., Huff, A. S. \& Thomas, H. ( 1992). Strategic renewal and the interaction of cumulative stress and inertia. Strategic Management Journal, 13, 55-75. doi: I0.1002/smj.4250131006

Jacobides, M. G. (2005). Industry change through vertical disintegration: How and why markets emerged in mortgage banking. Academy of Management Journal, 48(3), 465-498. doi: I0.5465/amj.2005. 17407912

Janssen, C. I. (20I3). Corporate historical responsibility (CHR): Addressing a corporate past of forced labor at Volkswagen. Journal of Applied Communication Research, 4I(I), 64-83. doi: 10.1080/00909882. 2012.731698

Kerman, J. (199|). Retrofitting blade runner: Issues in Ridley Scott's blade runner and Philip K. dick's do androids dream of electric sheep? Bowling Green State University Popular Press.

Ketokivi, M., Mantere, S. \& Cornelissen, J. (2017). Reasoning by analogy and the progress of theory. Academy of Management Review, 42(4), 637-658. doi: I0.5465/amr.20I5.0322

Kim, H. E. \& Pennings, J. M. (2009). Innovation and strategic renewal in mature markets: A study of the tennis racket industry. Organization Science, 20(2), 368-383. doi: 10.1287/orsc. 1080.0420 
Knott, A. M. \& Posen, H. E. (2009). Firm R\&D behavior and evolving technology in established industries. Organization Science, 20(2), 352-367. doi: 10.1287/orsc. 1070.0332

Kotter, J. P. (1995/20 I2). Leading change. Harvard Business Press.

Lamberg, J. A., Lubinaite, S., Ojala, J. \& Tikkanen, H. (2020). The curse of agility: The Nokia Corporation and the loss of market dominance in mobilephones,2003-20 I 3.Business History.doi: I 0. I 080/00076791.2019. 1593964 [forthcoming].

Lem, S. (1975). Philip K. Dick: A visionary among the charlatans. Science Fiction Studies, 2(I), 54-67.

Lubinski, C. (20 I8). From "history as told" to "history as experienced": Contextualizing the uses of the past. Organization Studies, 39(12), 1785-1809. doi: |0.1177/01708406|8800116

McKinley, W., Latham, S. \& Braun, M. (20।4). Organizational decline and innovation:Turnarounds and downward spirals. Academy of Management Review, 39(I), 88-। I0. doi: I0.5465/amr.20 I I.0356

Mey, T. D. \& Weber, E. (2003). Explanation and thought experiments in history. History and Theory, 42( I), 28-38. doi: I 0. I I I / | 468-2303.00227

Miller, K. D., Gomes, E., \& Lehman, D.W. (2019). Strategy restoration. Long Range Planning, 52(5), 101855.

Minkowski, H. (20 I 2). Space and time. In V. Petkov (Ed.), Space and time: Minkowski's papers on relativity (pp. 39-56). Minkowski Institute Press.

Morrow, J. L., Sirmon, D. G., Hitt, M. A. \& Holcomb, T. R. (2007). Creating value in the face of declining performance: Firm strategies and organizational recovery. Strategic Management Journal, 28, 27 I-283. doi: I 0. I 002/smj.579

Ndofor, H. A., Vanevenhoven, J. \& Barker, V. L. (20I3). Software firm turnarounds in the 1990s: An analysis of reversing decline in a growing, dynamic industry. Strategic Management Journal, 34, | |23-| | 33. doi: 10.1002/smj.2050

Pandit, N. R. (2000). Some recommendations for improved research on corporate turnaround. M@n@gement, 3(2),31-56.

Parker, M., Higgins, M., Lightfoot, G. \& Smith, W. (1999). Amazing tales: Organization studies as science fiction. Organization, 6(4), 579-590. doi: | 0.1 1 177/|3505084996400 |

Pearce, J.A. \& Robbins, K. (1993). Toward improved theory and research on business turnaround. Journal of Management, 19(3), 613-636. doi: I 0.1 1 177/014920639301900306

Petkov, V. (20 I2). Introduction. In V. Petkov (Ed.), Space and time: Minkowski's papers on relativity (pp. I-38). Minkowski Institute Press.

Raffaelli, R. (2018). Technology reemergence: Creating new value for old technologies in Swiss mechanical watchmaking, 1970-2008. Administrative Science Quarterly, 64(3), 576-618. doi: 10.1 I77/000 I839218778505

Robbins, D. K. \& Pearce, J. A. (1992). Turnaround: Retrenchment and recovery. Strategic Management Journal, 13(4), 287-309. doi: 10.1002/ smj.4250I 30404

Rowlinson, M. \& Hassard, J. ( 1993). The invention of corporate culture: A history of the histories of Cadbury. Human Relations, 46(3), 299-326. doi: | 0.1 | 77//00 | 87267930460030 |

Sasaki, I., Kotlar, J., Ravasi, D. \& Vaara, E. (2020). Dealing with revered past: Historical identity statements and strategic change in Japanese family firms. Strategic Management Journal, 41, 590-623. doi: 10.1002/ smj.3065

Schmitt, A., Barker,V. L., Raisch, S. \& Whetten, D. (2016). Strategic renewal in times of environmental scarcity. Long Range Planning, 49(3), 36 I-376. doi: | 0. I | | 6/j.Irp.20 I5.08.004
Schmitt, A. \& Raisch, S. (20/3). Corporate turnarounds: The duality of retrenchment and recovery. Journal of Management Studies, 50(7), | 2 | 6-1244. doi: | 0.1 | | | /joms. 12045

Schmitt, A., Raisch, S. \& Volberda, H. W. (20।8). Strategic renewal: Past research, theoretical tensions and future challenges. International Journal of Management Reviews, 20(I), 81-98.

Schmitt,A., Barker III,V. L., Raisch, S., \&Whetten, D. (20 I 6). Strategic renewal in times of environmental scarcity. Long Range Planning, 49(3), 36 I-376.

Sinha, P. N., Jaskiewicz, P., Gibb, J. \& Combs, J. G. (2020). How New Zealand's Gallagher group used rhetorical narratives to reprioritize and modify imprinted strategic guideposts. Strategic Management Journal, 4I, 557-589. doi: 10.1002/smj.3037

Skow, B. (20I5). Objective becoming. Oxford University Press.

Stopford, J. M. \& Baden-Fuller, C. (1990). Corporate rejuvenation. Journal of Management Studies, 27(4), 399-4I5. doi: 10.1 I I I/j.I467-6486. 1990. tb00254.x

Suddaby, R. (2016). Toward a historical consciousness: Following the historic turn in management thought. M@n@gement, 19(I), 46-60. doi: 10.3917/mana.191.0046

Suddaby, R., Bitektine, A. \& Haack, P. (2017). Legitimacy. Academy of Management Annals, I I ( I), 45 I-478. doi: I0.5465/annals.20 I5.0 I 0 I

Suddaby, R. \& Foster, W. M. (2017). History and organizational change. Journal of Management, 43(I), | 9-38. doi: I 0.1 I77/0 I 492063 | 667503 |

Suddaby, R., Foster, W. M. \& Trank, C. Q. (20I0). Rhetorical history as a source of competitive advantage. Advances in Strategic Management, 27, I47- 173. doi: I0.1 108/S0742-3322(20 I 0)0000027009

Tangpong, C., Abebe, M. \& Li, Z. (20 I 5). A temporal approach to retrenchment and successful turnaround in declining firms. Journal of Management Studies, 52(5), 647-677. doi: 10.11 | I /joms. 12131

Trahms, C.A., Ndofor, H.A. \& Sirmon, D. G. (20 I3). Organizational decline and turnaround: A review and agenda for future research. Journal of Management, 39(5), 1277-1307. doi: I0.1 I 77/01492063 I247/390

Vaara, E. \& Lamberg, J.-A. (2016). Taking historical embeddedness seriously: Three historical approaches to advance strategy process and practice research. Academy of Management Review, 4 I (4), 633-657. doi: I0.5465/ amr.2014.0172

Vanderbilt,T. (2019, November). Brand illusions:Why a gin maker invented its own history. The Economist, Retrieved from https://www.economist. com/ I 843/201 9/09/06/why-a-gin-maker-invented-its-own-history

Wadhwani, R. D., Kirsch, D.,Welter, F., Gartner,W. B. et al. (2020). Context, time, and change: Historical approaches to entrepreneurship research. Strategic Entrepreneurship Journal, I 4(I), 3-19. doi: 10. I002/sej. 1346

Wadhwani, R. D., Suddaby, R., Mordhorst, M. \& Popp, A. (2018). History as organizing: Uses of the past in organization studies. Organization Studies, 39(12), | 663-1683. doi: | 0.1 1 177/01708406188|4867

White, H. (2005). Introduction: Historical fiction, fictional history, and historical reality. Rethinking History, 9(2-3), 147-157. doi: 10.1080/ | $3642520500 \mid 4906$ |

Wiesen, S. J. (2003). West German industry and the challenge of the Nazi past, 1945-1955. University of North Carolina Press.

Ybema, S. (2014). The invention of transitions: History as a symbolic site for discursive struggles over organizational change. Organization, 21 (4), 495-5 | 3. doi: | 0.1 I 77// 3505084|4527255

Zundel, M., Holt, R. \& Popp, A. (2016). Using history in the creation of organizational identity. Management \& Organizational History, II (2), 2। I-235. doi: I0. 1080/17449359.20 I 5. I 124042 